\title{
An Analysis of English Language Theories: A Case Study
}

\author{
Ali Ata Alkhaldi*, Tamara Oshchepkova \\ American University of the Middle East, Kuwait \\ Corresponding Author: Ali Ata Alkhaldi , E-mail: Ali.al-khaldi@aum.edu.kw
}

\section{ARTICLE INFO}

Article history

Received: April 04, 2018

Accepted: July 07, 2018

Published: August 31, 2018

Volume: 9 Issue: 4

Advance access: July 2018

Conflicts of interest: None

Funding: None

Key words:

Materials Analysis,

Language Theories,

Materials Development,

Professional Development

\begin{abstract}
Language is implicated in daily lives, and there are a large and open-ended number of activities (Cook, 2003), which involve language theories (Alkhaldi, 2011). This research analyses the language theories which are involved in the activities of Jordanian language materials. The researchers have chosen a sample from language materials used to teach English at Jordanian public high schools since 2015. An analysis checklist has been adapted and used, focusing on the analysis of language theories. The findings show that the students' role is responsive rather than proactive. The dominant source of content is the materials, and the teachers' role is overlooked in providing useful language content. Furthermore, the mental operations have not been taken to the deepest level to promote students' creative and critical thinking skills. The findings also reveal that the materials have a sentence-based content, that is, the content provided as input to learners and content expected as output from the learners comprise individual words, phrases and sentences, and there are few opportunities for extended written and oral discourse. Consequently, it is recommended that teachers, researchers and materials developers should take into consideration such challenging findings to bridge the gap between theory and practice and to develop language materials effectively. In other words, the materials should continuously be analysed, evaluated, and developed in a systematic and rigorous way to have insights into the materials and the process of analysis for professional development purposes, and to help students improve their language learning process.
\end{abstract}

\section{INTRODUCTION}

\section{Background of the Study}

The analysis process is an objective description that aims to provide important information about the target language materials and the applied linguistics theories (Cunningsworth, 1995; Tomlinson, 1999, 2011; McGrath, 2002; and Littlejohn, 2011). Littlejohn (2011), for example, argues that there is a need for analysing materials closely; therefore, the researchers can see 'inside' them and take more control over their design and use. In other words, the materials analysis can provide insights into effective practice, and it may help in determining the validity of language theories.

Textbooks generally provide a necessary site for the study of theories (Basturkman1999). The claims being made for textbooks on the introduction, back cover, and/or table of contents need to be tested (Littlejohn, op.cit.; Cunningsworth, op.cit.; Basturkman, op.cit.; and McGrath, op.cit.). The language and learning theoretical views and what constitutes content should potentially be surmised from the blurbs of the textbook or teacher's book which are considered a key site for the visibility of the theories (Basturkman 1999). Therefore, textbooks are potentially an important site for studying theories and claims about language, learning and teaching (Alkhaldi, 2011).

\section{Rationale of the Study}

According to the researchers' best knowledge, students in Jordan usually complain about the difficulty of learning English and the continuous change of the textbooks (Alkhaldi, 2011). He maintains that there is 'a research gap' between the Jordanian research context and the findings of Second Language Acquisition (SLA) research. Furthermore, there are high quality materials to help learners learn English, but learners are not able to achieve a satisfactory level of communicative competence (Tomlinson, 2011). Consequently, there is a need to analyse the materials to have insights into the language theories, authors' claims, and the materials themselves.

\section{Significance of the Study}

Publishers often try to achieve commercial benefits because they are primarily motivated by financial success (Dat, 2006 \& Richards, 2001). It is important, therefore, to analyse the textbooks to identify their effectiveness. Moreover, materials design has recently been characterised by two important developments: firstly, published materials are now used more widely than ever before; secondly, and it is this which makes the spread of published materials very significant, materials themselves have evolved into much more complex 
objects (Littlejohn, op. cit.), and this necessitates a means of analysing the textbooks. Alkhaldi (2010) also indicates that the strengths and weaknesses of English language theories can be assessed according to their theoretical and pedagogical strengths. As a result, this research aims to identify the strengths and weaknesses of commercial textbooks used in a real environment and to provide the researchers and teachers with a database for professional training purposes.

\section{Purpose of the Study}

Analysis can be a useful tool for the selection of materials (Littlejohn, op. cit., Cunningsworth, op. cit., Tomlinson, 2011, McGrath, op. cit., and Mukundan, 2006). Analysis can also throw light on underlying beliefs, theories and claims (Alkhaldi, 2011). The main purpose of this study is to gain insights into the process of analysis and the content of the Jordanian materials by identifying the validity of language theories and test out the authors' claims in a systematic and rigorous way. As a result, such insights may support materials developers, researchers and teachers in their professional development training about the textbook analysis and materials development to better achieve the purpose of using the materials, that is, effective language learning. McGrath (op. cit.) argues that the purpose of analysis is to provide a description, but such a description can be at different levels of sophistication. He maintains that materials analysis can be used as an alternative to an evaluation checklist or in conjunction with an evaluation checklist. The analysis may help researchers and teachers identify the strengths and weaknesses of their textbooks, test the validity of the authors' claims, and find out the potential mismatch between Jordanian learners' levels and their materials and/or between theory and practice (Alkhaldi, 2011).

\section{LITERATURE REVIEW}

The related literature has been reviewed and summarised. It focuses on discussions about the analysis of the materials: methods of analysis, the Jordanian educational background, and the role of English language materials.

\section{Methods of Analysis}

There are several methods of analysis. While some researchers have discussed two methods, others have discussed three or four methods. The methods of analysis have been summarised as the following:

1. The first method: It has different names, but it generally has the same purpose. It is called the impressionistic method or approach (Cunningsworth, op. cit. and McGrath, op. cit.). It is called the first materials evaluation stage, 'external materials evaluation' (McDonough and Shaw, 2003), and also 'Level 1 analysis' (Littlejohn, 2011). This method is useful for obtaining an overview of the organisational principles involved $(\mathrm{McD}$ onough and Shaw, op. cit.). It involves glancing at the description of the book on the back cover and also the contents page, and then skimming the book, observing the organ- isation, topics, layout and visuals (McGrath, op. cit.). There is explicitly a consideration of 'what is there' in the materials (Littlejohn, 1992). This category is useful for having a general overview of the materials, but the examination is only at the surface level. As a result, it needs to be supported by other detailed categories of analysis.

2. The second method: It is sometimes called the checklist method. Like the impressionistic method, it is not a watertight category (McGrath, op. cit.). However, it seems to be very different from the impressionistic approach. He maintains that a checklist includes items for comparison, identification or verification, with the items being ticked once their presence has been confirmed. It has several advantages. It is systematic, cost effective (permits information to be recorded in a short space of time), the information is recorded in a convenient format (for easy comparisons), and it is explicit. However, it has its limitations; the systematicity is a strength only if the criteria are relevant to the specific context in which the checklist is to be used. An 'off-the-shelf' checklist will possibly need tailoring to fit a particular context, and this can involve more than omitting the items of the checklist which are inapplicable.

3. The third method: It is called in-depth method or approach (Cunningsworth, op. cit. and McGrath, op. cit.). It is called the second stage of materials evaluation, 'the internal evaluation' (McDonough and Shaw, op. cit.), and also 'Level 2 analysis' (Littlejohn 1992, 2011). McDonough and Shaw (op. cit.) suggest that the internal materials evaluation is a detailed evaluation to see how the materials in question match up to the authors' claims, as well as the aims and objectives of a given program of English teaching. Cunningsworth (op. cit.) also argues that the in-depth approach is characterised by its active nature; researchers seek out information actively about the materials. The techniques of in-depth analysis go beneath the claims of the publishers and authors to look at the language description kind; underlying claims about the process of learning or values on which the materials are based (McGrath, op. cit.). This method is very useful to get detailed data and reliable findings of the analysed textbooks; therefore, the researchers of this study conducted such an analysis.

4. Conclusion: Providing conclusion in light of the findings. It is called the overall evaluation (McDonough and Shaw, op. cit.), it is called the conclusion (Cunningsworth, op. cit. and McGrath, op. cit.), and it is also called the third level of analysis (Littlejohn 1992, 2011). The analysts, at this level, may come to the conclusion about the role of the materials in facilitating the process of language learning (Littlejohn 1992, 2011), and identifying the validity of the language theories.

The writers of the aforementioned articles and books discuss similar ideas concerning the methods of analysis which possibly causes confusion for researchers. Notably, the first materials evaluation stage of McDonough and Shaw (op. cit.) 'external materials evaluation'; 'The impressionistic 
method/approach' of McGrath (op. cit.) and Cunningsworth (op. cit.); 'Level 1 analysis' of Littlejohn $(1992,2011)$ are potentially similar to each other, that is, their aim is to have a general overview of the materials and this can be done easily through examining the introduction or the back cover of the book. Likewise, the second stage of materials evaluation of McDonough and Shaw (op. cit.), 'The internal evaluation'; 'In-depth Analysis' of McGrath (op. cit.) and Cunningsworth (op. cit.); and 'Level 2 analysis' of Littlejohn (1992, 2011) are similar. The aim of this level of analysis or stage is to provide specific or detailed information about the materials before using them (i.e. for selection purposes) and/or during the use of the materials. This study has conducted such an analysis to gain a deeper understanding of the materials, language theories, and authors' claims.

McDonough and Shaw (op. cit.) identify two types of materials evaluation; external evaluation, and internal evaluation., Their discussion seems to be confusing in as much as they discuss evaluation when they mean analysis according to other definitions (e.g., Alkhaldi, 2011). Consequently, they do not sufficiently distinguish between evaluation and analysis. Finally, they have discussed the overall evaluation, conclusion, or third level of analysis that leads to useful results or statements about the analysed materials. However, it seems that there is an overlap between Littlejohn's stages of analysis and others who call such stages materials evaluations. The following table summarises the stages and aims of analysis:

Table 1 shows the types and aims of analysis. In the first stage, the analysis methods (impressionistic method/external evaluation/level 1 of analysis) provide a general overview about the materials and this type of analysis might purposefully be used for materials selection. The second stage; includes the analysis methods (In-depth method, the internal evaluation, or Level 2 analysis), and the common issue is to examine the value of the existing materials. In the third stage, the common issue between analyses is likely to determine the validity of language theories, authors' claims, and insights about the process of the analysis.

\section{Jordanian Educational Background}

English is taught as a foreign language at Jordanian state schools, whereas it is used as a medium of instruction in some universities. Jordanian students start learning the English language from the beginning of their schooling life, that is, from the first basic grade at the age of six-year old or earlier until they finish their secondary education at the age of eighteen or nineteen. The first stage, the basic stage, consists of the first ten basic grades. The second stage, the secondary stage, consists of two secondary grades, eleventh and twelfthgrades. Since 2015, the Ministry of Education in Jordan has prescribed new materials to be taught called "Action Pack" for grade twelve.

\section{The Role of English Language Materials in Jordan}

It is necessary to note that the term 'language materials' has several definitions (Alkhaldi, 2010). The textbook is the main component of the materials, and the researchers of this study use the term 'materials' to refer to the textbook(s). Jordanian learners at state schools rely predominantly on published or commercial materials to learn the English language. The textbook, is essential because it "fulfils a need, a purpose, it performs a function, conveys meaning.... language and textbooks do not exist in a vacuum - they exist for and are shaped by a purpose within a particular context of use, culture and ideology" (Wala, 2003: 60), i.e. the textbook does not exist in isolation (Mukundan, 2006). There could be a lengthy discussion about the potential advantages and disadvantages of the language materials, but such a discussion may not be necessary in a context where materials have to be standardized such as the Jordanian context.

\section{METHODOLOGY}

While it might be useful to look through the textbook quickly and form a general impression of its possibilities and its potential strengths and weaknesses, the researchers need more detailed analysis of the textbook (Cunningsworth, op.cit.). Littlejohn (2011) argues that the researchers need to be able to investigate the implications that the use of textbooks may have for the work of the classroom, so they can decide whether the methodology and content of the materials is adequate for a particular context or not. He maintains that the researchers need a means of looking 'inside the Trojan horse'. Therefore, he recommends that the researchers need a general framework which allows textbooks to 'speak for themselves'.

Table 2 presents the level of analysis in his framework which focuses on the content of the materials and their methodology (based on Littlejohn 1992, 2011)

Although the framework consists of three main levels, the researchers of this study have adapted the framework, adopted level 2 of analysis above and omitted the other levels. The rationale for this choice is that level 2 of analysis

Table 1. Summary of the stages and aims of analysis

\begin{tabular}{lll}
\hline Stages & Type of analysis & The aim(s) \\
\hline Stage 1 & $\begin{array}{l}\text { Impressionistic method, external evaluation, or } \\
\text { Level 1 analysis. }\end{array}$ & Have a general/impressionistic overview of the materials. \\
Stage 2 & $\begin{array}{l}\text { In-depth method, the internal evaluation, or Level } \\
2 \text { analysis. }\end{array}$ & $\begin{array}{l}\text { Gain details of the language description of the new and/or existing } \\
\text { materials, underlying claims about the process of learning or } \\
\text { values on which the materials are based. }\end{array}$ \\
Stage 3 & $\begin{array}{l}\text { The conclusion, the overall evaluation, or level } 3 \\
\text { of analysis. }\end{array}$ & $\begin{array}{l}\text { To draw conclusions about the role of materials in facilitating } \\
\text { teaching and learning the language. }\end{array}$ \\
\hline
\end{tabular}


is significant to analyse extracts of the materials in depth. It also covers a useful variety of tasks and informs the researcher as to what is required from learners. The researchers of this study have omitted level 1 and 3 of analyses since the main focus is to analyse the existing materials in depth. In other words, the purpose of the adaptation is to gather detailed information that helps in obtaining deeper understanding of the process of materials analysis.

With regard to the analysed extracts of the textbooks, it has been suggested that researchers should analyse one unit in detail. (Cunningsworth, 1995), and Littlejohn (2011) found it is useful to analyse about $10 \%$ to $15 \%$ of the total textbooks, and the unit(s) should ideally be chosen around the midpoint. The researchers of this study analysed one unit of grade twelve around the midpoint (See unit 5 in the following link http://www.moe.gov.jo/Files/Jordan-Action $\% 20$ Pack\%2012-SB.pdf).

With regard to tasks in Littlejohn's framework, there are many attempts to define the term "task". However, there is no conclusive agreement on the definition of the term (e.g. Ellis, 2003). Littlejohn (2011), for example, argues that the definition of the task that refers to meaning-focused work, such as projects and problem solving, will be too narrow for a general analysis framework of language learning textbooks, as it will not be applicable to textbooks which are not meaning-focused.

He proposes an alternative broader definition of task (based on Breen and Candlin's definition in 1987) as the following: "task refers to any proposal contained within the materials for action to be undertaken by the learners, which has the direct aim of bringing about the learning of the foreign language" (2011, p.188). He maintains that this broad definition needs further details to enable researchers to concentrate on the various aspects within tasks. He identifies three important aspects in the nature of the task: 1) a process through which the learners are expected to go; 2) a mode of classroom participation concerning with whom (if anyone) the learners are to work; 3) content upon which learners are to engage or focus on (due to this current study's word limit, aspects of the tasks and their definitions are available in Littlejohn, 1992 \& 2011).

Using such a detailed definition, it will now be possible to analyse extracts of the Jordanian textbooks. The figure below summarises the potential sub-features for the basis of the detailed analysis of tasks, phrased as questions that can potentially address the language textbooks. The questions can be put to each task of the extract, reflecting the three aspects of process, participation and content:

Littlejohn (2011) explains that the first question in Figure 1 relates to the 'process' that allows analysts to concentrate, in detail, on what the learners are expected to do. The main body of analysis within this question relates to operation 'what it is that the learner is required to do?' The second question within the proposed checklist relates to classroom participation; 'With whom?' The reason for such a question is that there is largely a considerable amount of literature within the profession of language teaching about the value of group and pair work. The third question in the checklist asks about task content; it relates to the nature of the subject matter with which learners are to work. To gain an overall picture of the materials, the researcher should calculate percentages for each feature (See Appendix A).

\section{FINDINGS AND DISCUSSION}

The obtained data has been analysed, and the findings have been discussed in this section to provide insights for teachers, researchers, and materials developers. The researchers of this study have analysed and described the aspects of materials which involve 'subject matter and focus' and 'types of learning and teaching activities'. Lastly, they provide recommendations based on the results to be taken in to consideration.

\section{Data Analysis}

The researchers analysed a unit of the grade twelve textbook. Table 3 presents the percentages of tasks regarding the first question in the analysis checklist:

1. What is the learner expected to do?

A Turn-take

B Focus

C Operation

2. With whom?

3. With what content?

A Form

$$
\begin{aligned}
& \text { - input to learners } \\
& \text { - output by learners }
\end{aligned}
$$

B Source

C Nature

Figure 1. A Summary of the sub-features for the analysis of tasks

Table 2. Analysis of the textbooks

\begin{tabular}{ll}
\hline Level & The features and examples of the Level \\
\hline 'What is required & An analysis of tasks \\
of users' & Question 1: 'What is the learner expected to do?' \\
& Turn-take: What the learner has to do; are they responding to questions, are they asked to "initiate", or are they \\
& not required to take any direct role. \\
& Focus: whether the learners are asked to focus on the meaning, the form or both. \\
& Operation: what operations, 'mental process', will be required (e.g. repetition, deduction rules, etc.). \\
& Question 2: 'With whom?' This asks about classroom organisation (e.g. individual work, pair/group work or with \\
& the whole class) \\
& Question 3: 'With what content?' Is it spoken or written? Where does it come from? And what is its nature? \\
\hline
\end{tabular}


Table 3 shows interesting findings of the analysis of the extracts. Under A Turn Take, the tasks that place learners in a 'Respond' position is evident (the average is 96.15\%), whereas the tasks that place learners in 'Initiate' position is low (the average is $3.85 \%$ ). Under B Focus, the tasks require learners to focus on meaning (average 65.38\%), meaning/system relationship (average $15.39 \%$ ), and the system of the language (average 19.23\%). In other words, the attention of the learners is required to be focused more on the meaning of the language rather than meaning/system relationships. There is a range of mental operation but it is not very widely spread in this analysis since only 9 tasks were recorded. The dominant task is "Select Information" and "Attend to Example" with co-occurrence averages of $26.92 \%$ and $23.08 \%$, respectively. Content for the tasks spread equally to some extent across the following features: 'Retrieve from ST memory', 'Compare', 'Formulate items into larger content, and 'Decode semantic meaning' (average $7.69 \%$ ).

With regard to the second question in the analysis checklist 'With whom?', Table 4 presents the percentages of the tasks for the extract.

Table 4 shows the findings of the analysis of the tasks that relate to the classroom participation proposed by the textbook. Higher scores are evident for features that involve "Learners individually simultaneously" (average 80.77\%). However, there is a low score for work that should be implemented in pairs/groups (average 19.23\%).

Regarding the third question of the analysis checklist, 'With what content?' and the fourth question 'Who decides?' the source of the content, Table 5 presents the averages of

Table 3. Percentages of tasks and their averages regarding 'What is the learner expected to do?'

\begin{tabular}{lc}
\hline 1 WHAT IS THE LEARNER EXPECTED TO DO? \\
\hline A TURN-TAKE & Average \\
\hline Initiate & 3.85 \\
Respond & 96.15 \\
Not required & 0 \\
\hline B FOCUS & Average \\
\hline Language system (rules or form) & 19.23 \\
Meaning & 65.38 \\
Meaning/system relationship & 15.39 \\
\hline C MENTAL OPERATION & Average \\
\hline Retrieve from ST memory & 7.69 \\
Attend to example, explanation & 23.08 \\
Draw on prior knowledge & 11.538 \\
Compare & 7.69 \\
Decode semantic meaning & 7.69 \\
Select information & 26.92 \\
Repeat with expansion & 15.38 \\
Deduce language rule & 11.538 \\
Apply stated language rule & 15.384 \\
Formulate items into larger content & 7.69 \\
\hline
\end{tabular}

the tasks for the extracts of grade eleven and twelve and the average.

The researchers calculated the percentage for each feature of the extracts, based on feature counts (See Appendix B). In other words, the aspects were located in the extracts and marked on a separate sheet of paper. Afterwards, the percentages of aspects were calculated and shown in the tables above. Following this, the researchers calculated the average of the extracts. The findings in Table 5 are interesting since they reveal important information for materials developers. Input content of the textbooks occurs as words, phrases or sentences with a co-occurrence average of $61.54 \%$ for written input and $15.38 \%$ for oral input. The findings also show the textbooks lack of 'Extended discourse'; (the average of written and oral extended discourse is $15.38 \%$ and $3.85 \%$, respectively).

The output expected from learners is also at the level of words, phrases or sentences with an average of $30.77 \%$ of

Table 4. Percentages of tasks and their average regarding 'With whom?'

\begin{tabular}{lc}
\hline II WITH WHOM? & Average \\
\hline Learner to class & 0 \\
Learners individually simultaneously & 80.77 \\
Learners in pairs/groups & 19.23 \\
\hline
\end{tabular}

Table 5. Percentages of tasks and their average regarding 'With what content?' and 'Who decides?'

\begin{tabular}{lc}
\hline III WITH WHAT CONTENT & \\
\hline A FORM & Average \\
\hline 1 input to learners & 3.85 \\
\hline Graphic & 61.54 \\
Words/phrases/sentences: written & 15.38 \\
Words/phrases/sentences: oral & 15.38 \\
Extended discourse: written & 3.85 \\
Extended discourse: oral & Average \\
\hline 2 expected output from learners & 0 \\
\hline Graphic & 30.77 \\
Words/phrases/sentences: written & 57.69 \\
Words/phrases/sentences: oral & 3.85 \\
Extended discourse: written & 7.69 \\
Extended discourse: oral & Average \\
\hline B SOURCE Who decides? & 88.46 \\
\hline Materials & 0 \\
Teacher & 11.54 \\
Learner(s) & Average \\
\hline C NATURE & 11.54 \\
\hline Personal opinion & 76.92 \\
Non-fiction & 0 \\
Fiction & 11.54 \\
Personal information & 0 \\
Metalinguistic comment & \\
\hline & \\
\hline
\end{tabular}


written output and $57.69 \%$ of oral input. The output of learners' extended discourse is also very low (the average of the output of written and oral extended discourse is $3.85 \%$ and $7.69 \%$ respectively).

With regard to the fourth question 'Who decides' the source of the content, the materials are dominant (average $88.46 \%$ ), but the learners do generate content (average $11.54 \%$ ). However, $23.08 \%$ of the learner-generated content is personal opinion and information. The teachers' role in generating the content is not emphasised at all. The dominant nature of content is 'Non-fiction' with an average of $76.92 \%$. 'Metalinguistic comment' and 'Fiction' have not been emphasised.

\section{Description of the Materials and Discussion}

After taking into account the findings of the analysis of the tasks, the researchers have described the relevant aspects of materials which involve subject matter and focus, types of learning and teaching activities and participation:

\section{Subject matter and focus of subject matter}

McDonough and Shaw (op. cit.) suggest that the internal materials evaluation helps the researchers to see how the materials in question match the authors' claims, as well as the aims and objectives of a given program of English teaching. One of the key emerging findings from the analysis of the tasks is that the content provided as input to learners and content expected as output from the learners comprise individual words, phrases or sentences. This finding does match the authors' claim which is "Action Pack 12 consists of six thematic modules based on a carefully graded syllabus. This approach will make it possible for students to develop all four language skills: listening, speaking, reading, and writing" (Pelteret, Kilbey, \& Greet, 2015b, p.6). To develop discourse skills, it is important to provide the learners with opportunities to give prepared, extended presentations in class (Nunan, 1999). However, the features of written and oral extended discourse in the analysed samples do not provide adequate opportunities of extended discourse, in particular, the output expected from the learners. This means that this finding may not support one of the language theories which is that materials should involve relevant content for the target learners' needs (e.g., Tomlinson, 2011). This finding suggests that the materials should provide the learners with an appropriate variety of useful discourse samples to be able to use and master all language skills (Alkhaldi, 2011).

Based on the findings of SLA, one of the language theories that should be included in the materials or applied in language materials development is that the materials should be flexible in order to give the opportunity for teachers to adapt the materials to suit their learners' needs and interests (e.g., Richards op. cit. \& Alkhaldi, 2011). Nevertheless, the dominant source of content is the materials themselves. There is learner-contributed content but, it is noteworthy, that there is no teacher-contributed content. Content is generally non-fiction content and metalinguistic comments, accounting on average for $37.45 \%$ and $22.98 \%$, respectively, of tasks. Personal opinions and information of the learners account for less than a quarter, whilst fiction may not be emphasized well in the materials, suggesting that creative thinking has not been taken into serious consideration. This shows that the analysed materials may not provide teachers with methodological support to facilitate their job and provide inspiration to them to articulate creative teaching methods or ideas as recommended by some researchers (e.g., Cunningsworth, op. cit.; McGrath op. cit.; and Mukundan, 2009).

\section{Types of learning and teaching activities}

A further language theory is that materials should help learners develop their confidence and independence (e.g., Tomlinson, 2011 \& Alkhaldi, 2011). However, the emerging finding from the analysis of tasks indicates that the textbook facilitates interaction in the classroom by putting learners in a predominantly 'Respond' position. It seems that the majority of tasks try to define or plan what the learners are to produce (written/oral production) and how they are to do this; reproducing the language that is provided by the materials is the main feature. This may occur as a repetition of language items and asking and answering question about them, or repetition of the activities in the materials themselves. The findings have revealed that the materials may limit the learners' initiative role and contributions. This also affects the teachers themselves whose role and contributions are overlooked.

The analysis of tasks also shows that the majority of tasks are reflected in the limited range of operations; nine basic operation types only. The cognitively demanding operations such as evaluating, hypothesizing and analysing have not been emphasised in the materials. The authors indicated in the teacher's book that "Critical Thinking has become a focus in the English language class along with the other language and study skills" (Pelteret, Kilbey, and Greet, 2015 b, p.12), but this has not been involved in the activities appropriately. In other words, this shows that the authors of the materials understand the related language theories that should be included in their materials such as providing the learners with useful content to engage the learners mentally and/or emotionally in the learning process (Alkhaldi, 2011), but they have potentially included critical thinking skills in the materials at the surface level.

Regarding language skills, the authors claimed that "Writing skills boxes have been included ... to help students develop their writing skills as much as possible... Action Pack 12 provides plenty of opportunity for practicing this skill (speaking)... The passages in each module provide useful controlled reading practice" (Pelteret, Kilbey, \& Greet, 2015b, pp.8-10). It seems that there is a mismatch between their claims and the reality of the materials. Regarding the productive skills of speaking and writing, 'expected output from learners', it is required from the learners to generate more oral language than written language. Nevertheless, both oral and written output are commonly based on words, phrases and sentences with little demand for learners to deal with extended discourse. With regard to the receptive skills of listening and reading, 'input to learners', the findings show that the emphasis is focused heavily on words, phrases or sentences. 
The findings of this research are similar to Alkhaldi's (2011) findings in which he analysed different materials for the same stage in Jordan in 2011. This means that the commercial adapted materials in Jordan may continuously be changed every period of time because of the continuous failure in achieving the main goal of adopting, adapting, and using new materials, which is effective language learning. It is highly recommended to consider the systematic analysis of materials in all stages when researchers and developers start evaluating and developing their materials.

\section{CONCLUSION}

The analysis in this study identified the strengths and weaknesses of the Jordanian materials, tested the validity of the authors' claims, provided professional training for teachers and researchers, and confirmed a mismatch between Jordanian learners' levels and their materials and/or between theory and practice. The analysis has revealed significant findings and revealed that some claims have been used for commercial purposes. The most salient points to emerge from the analysis are that the learners are responsive rather than being proactive and that the materials are sentence-based content with a lack of or few opportunities for extended discourse. In addition, there is no role for teachers in providing content, the textbook is the main source of content, and the dominant nature of the content is non-fiction. This means that the teacher's role might be restricted to delivering the content of the materials as it is, without having any opportunity or suggestion for teaching with options and/or supplementing/ enriching the content from, for example, their experience or other sources. The materials, however, could be more flexible by giving a key role for teachers to adapt the materials and/or provide related and interesting content. The learners have a role but it is responsive and based on their personal opinion and information. Furthermore, the materials might not have helped the learners to be engaged cognitively in learning the language, and there is a lack of tasks that focus on deep cognitive operations such as analysis and hypothesising. Such findings may shed light on the fact that the students may not be able to achieve a satisfactory level of communicative competence (Tomlinson, 2011) because there is potentially a mismatch between theory and practice (Alkhaldi, 2011).

Regarding the four language skills, particularly, the productive skills, the learners are required to generate more oral language than written language; however, both oral and written output are commonly based on words, phrases or sentences with little demand for learners to deal with extended discourse.

To conclude, the Jordanian materials may not satisfactorily provide a useful input for students and teachers to help them learn English language effectively as recommended by some scholars (e.g., McGrath, 2002). The authors and/or publishers of the materials might have achieved commercial benefits (e.g., Richards 2001). However, changing commercial materials every few years by the Jordanian Ministry of Education is not the solution to overcome the obstacles for effective language learning. The suggested solution is that the materials should continuously be analysed, evaluated, and developed in a systematic and rigorous way to gain insights about the process of analysis and the content of the materials, and to help students improve their language skills critically and creatively. Moreover, the materials writers and/ or developers should include a variety of useful samples of discourse in the materials to help the students meaningfully use the language for communicative and cognitive purposes (e.g., Tomlinson 2011). The materials should also help the learners to use their initiative and be creative in language learning rather than being responsive at the word, phrase, or sentence levels. As a result, taking such recommendations into consideration may help the teachers, researchers, and materials developers to bridge the gap between the learners and their materials and between the theory and practice.

\section{REFERENCES}

Alkhaldi, A. A. (2010). Developing a principled framework for materials evaluation: Some considerations. Advances in Language and Literary Studies, 1(2), 281-298. doi:10.7575/aiac.alls.v.1n.2p.281

Alkhaldi, A. A. (2011). Materials Development in Jordan: An Applied Linguistics Challenge. Unpublished doctoral dissertation, Leeds Beckett University, Leeds, UK.

Basturkman, H. (1999). A Content analysis of ELT textbook blurbs: Reflections of theory-in-use. RELC Journal, 30(1) pp.18-38.

Cook, G. (2003). Applied Linguistics. Oxford. Oxford University Press.

Cunningsworth, A. (1995). Choosing your Coursebook. Oxford: Heinemann.

Dat, B. (2006). Developing EFL materials for local markets: Issues and considerations. In: Mukundan, J. ed. Focus on ELT Materials (pp. 52-76). Petaling Jaya: Pearson Malaysia.

Ellis, R. (2003). Task-based Language Learning and Teaching. Oxford: Oxford University Press.

Littlejohn, A. (1992). Why are English language teaching materials the way they are? Unpublished Ph.D. thesis, Lancaster University.

Littlejohn, A. (2011). The analysis of language teaching materials: Inside the Trojan Horse. In: Tomlinson, B. (Ed.). Materials Development in Language Teaching ( $2^{\text {nd }}$ ed., pp.179-211). Cambridge: Cambridge University Press.

McDonough, J. and Shaw, C. (2003). Materials and Methods in ELT: A Teacher's guide. $2^{\text {nd }}$ ed. Oxford: Blackwell.

McGrath, I. (2002). Materials Evaluation and Design for Language Teaching. Edinburgh: Edinburgh University Press.

Mukundan, J. (2006). Are three new ways of evaluating ELT textbooks? In: Mukundan, J. ed. Readings on ELT materials II (pp.170-180). Petaling Jaya: Pearson Malaysia.

Mukundan, J. (2009). ESL Textbook Evaluation: A Composite Framework. Germany: Lambert Academic Publishing $\mathrm{AG}$ and Co. KG.

Pelteret, Ch., Kilbey, L., and Greet, J. (2015a). Action Pack Twelfth Grade, Student's Book. England: Pearson Education Ltd. 
Pelteret, Ch., Kilbey, L., and Greet, J. (2015b). Action Pack Twelfth Grade, Teacher's Book. England: Pearson Education Ltd.

Richards, J. (2001). Curriculum Development in Language Education. Cambridge: Cambridge University Press.

Tomlinson, B. (1999). Developing criteria for evaluating L2 materials. IATEFL Issues, 147, pp.10-13.
Tomlinson, B. (Ed). (2011). Materials Development in Language Teaching ( $2^{\text {nd }}$ ed.). Cambridge: Cambridge University Press.

Wala, D. A. S. (2003). A coursebook is what it is because of what it has to do: an editor's perspective. In: Tomlinson, B. ed. Materials development for language teaching (pp. 58-71). London, Continuum Press.

\section{APPENDICES}

\section{APPENDIX A}

\section{Textbook analysis checklist}

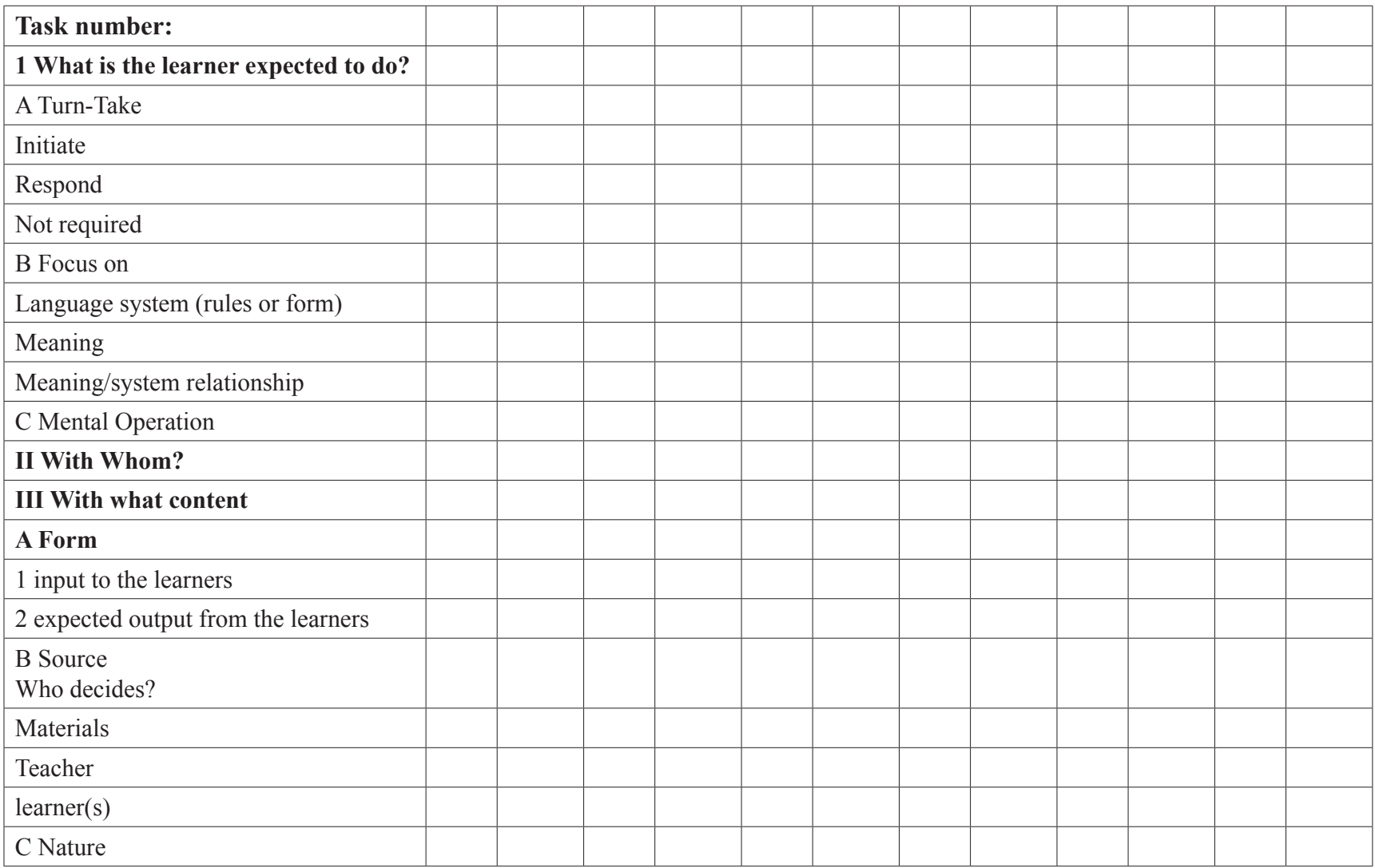




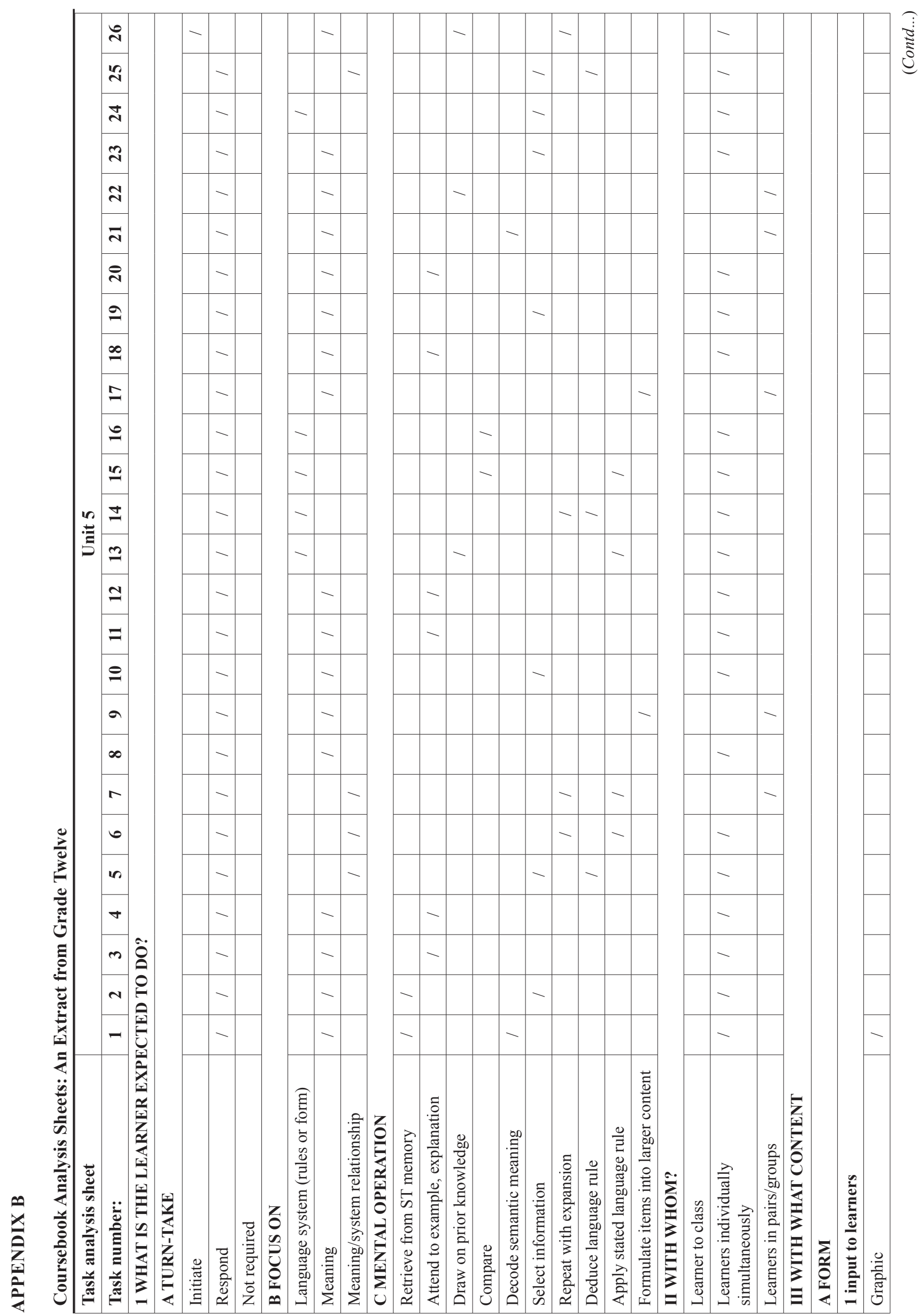




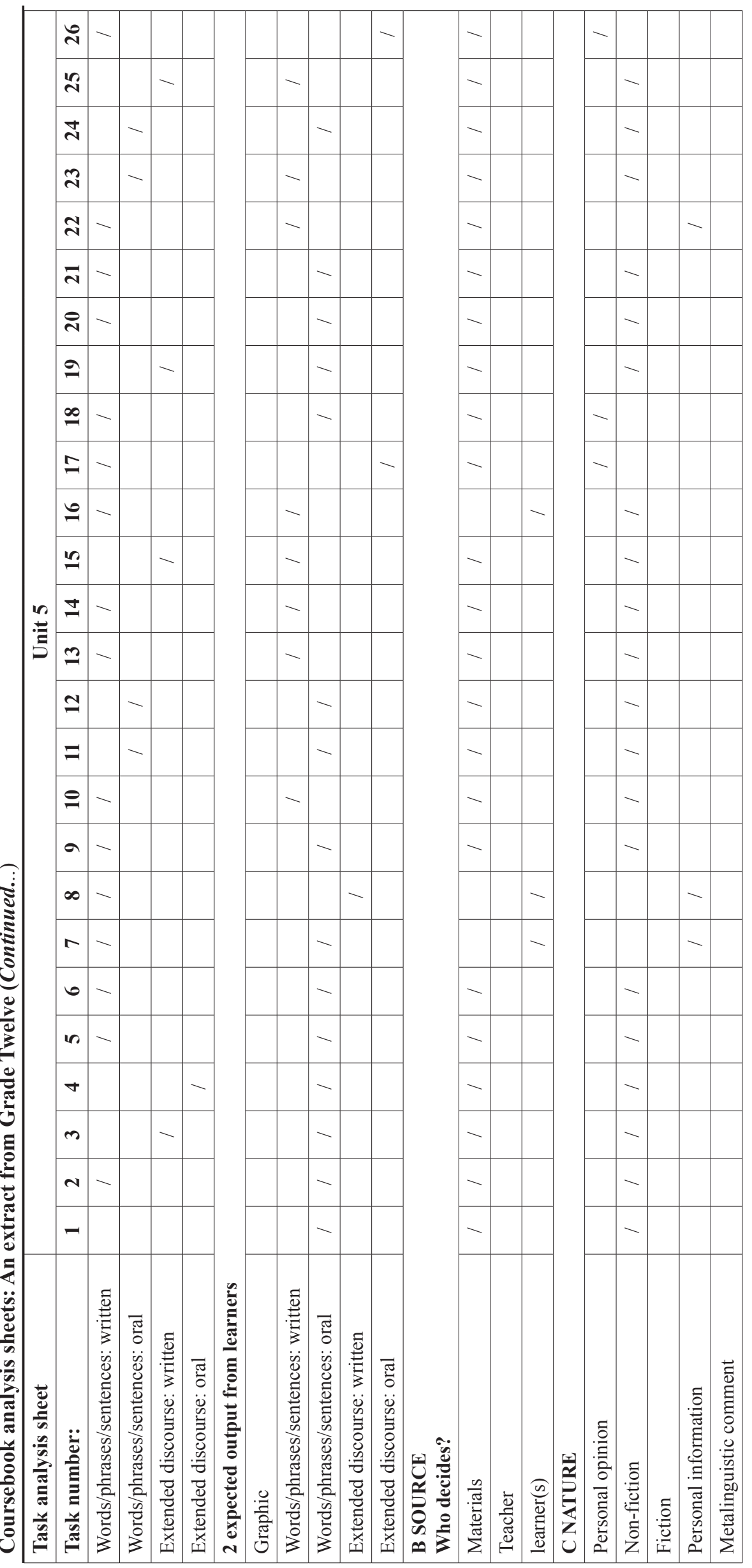

